University of Rhode Island

DigitalCommons@URI

Open Access Master's Theses

2013

\title{
Attachment and Self Regulation in Preschool Age Children
}

Kate M. Pearson

University of Rhode Island, Kate_Pearson@my.uri.edu

Follow this and additional works at: https://digitalcommons.uri.edu/theses

\section{Recommended Citation}

Pearson, Kate M., "Attachment and Self Regulation in Preschool Age Children" (2013). Open Access

Master's Theses. Paper 71.

https://digitalcommons.uri.edu/theses/71

This Thesis is brought to you for free and open access by DigitalCommons@URI. It has been accepted for inclusion in Open Access Master's Theses by an authorized administrator of DigitalCommons@URI. For more information, please contact digitalcommons-group@uri.edu. 


\section{ATTACHMENT AND SELF REGULATION IN PRESCHOOL AGE CHILDREN \\ BY \\ KATE M. PEARSON}

\section{A THESIS SUBMITTED IN PARTIAL FULFILLMENT OF THE \\ REQUIREMENTS FOR THE DEGREE OF \\ MASTERS OF SCIENCE \\ IN \\ HUMAN DEVELOPMENT AND FAMILY STUDIES}

UNIVERSITY OF RHODE ISLAND

2013 
MASTERS OF SCIENCE IN HUMAN DEVELOPMENT AND FAMILY STUDIES

THESIS

OF

KATE M. PEARSON

APPROVED:

Thesis Committee:

Major Professor___ Jaime Dice

$\frac{\text { Barbara Newman }}{\text { Bethany Hamilton Jones }}$

UNIVERSITY OF RHODE ISLAND

2013 


\begin{abstract}
Literature supports a relationship between attachment style and emotional regulation (Panfile \& Laible, 2012; Waters, Virmani, Thompson, Meyer, \& Jochem, 2010; Mikulincer, \& Shaver, 2005; Cassidy, 1994). Research also indicates that emotional regulation is linked to cognitive and behavioral regulation (Garner \& Waajid, 2012; Denham, Bassett, Way, Mincic, Zinsser, \& Graling, 2012; Tarullo, Obradovic, \& Gunnar, 2009; Ramani, Brownell, \& Campbell, 2010; Raver, Garner, \& Smith-Donald, 2007). However, existing literature surrounding attachment theory and various components of self-regulation is limited. The paucity of information available and lack of consensus about the definition of cognitive and behavioral regulation make them difficult constructs to examine. Furthermore, a relationship between attachment status and salient self-regulation abilities has never been studied individually. Insecurely attached infants have a harder time achieving emotional, behavioral and cognitive regulation when compared to their secure counterparts. This study examines the relationship between attachment status and self-regulation at preschool age by analyzing data from the Early Childhood Longitudinal Study -Birth Cohort. The Early Childhood Longitudinal Study-Birth Cohort is the most recent longitudinal data set that captures socio-emotional as well as physical development in a variety of caregiver settings for young children (Sparks, 2009; Kotelchuck, 2009; Paulson, Keef, \& Leiferman, 2009). Attachment was measured using the Toddler Attachment Sort-45 (Bimler \& Kirkland, 2002; Kirkland, Bimler, Drawneek, McKim, Schölmerich, \& Axel, 2004). Emotional, behavioral, and cognitive elements of self-regulation at preschool age were measured in Early Care and Education Provider interviews that incorporated elements of socio-
\end{abstract}


emotional development in the context of the environment. The final sample contained 2,650 children. Results indicated that self-regulation is significantly related to attachment status at preschool age. Securely attached preschoolers have overall higher self-regulation scores in most domains than insecurely attached preschoolers. Analysis of Covariance between self-regulation types and attachment style revealed significant relationships between secure attachment and high levels of emotional, behavioral, and cognitive regulation. Furthermore, pair wise comparisons revealed that ambivalent attached preschoolers have low levels of emotional self-regulation when compared to their secure and avoidant attached counterparts. Pairwise comparisons between attachment groups and self-regulation measures also revealed that avoidant attached infants experience low levels of cognitive regulation. The implications of these results are addressed in the discussion. 


\section{ACKNOWLEDGMENTS}

Upon completion of this Master's Thesis for graduation from the Human

Development and Family Studies program at the University of Rhode Island I would like to acknowledge several individuals who provided support and inspiration along the way. Thank you to Jaime Dice, major professor and principle investigator in this project, who guided my interests and provided me access to a comprehensive, exciting, and prestigious dataset. As my early childhood seminar professor, Dr. Dice took it upon herself to strike up conversation with me about my interest in attachment. She suggested thesis topics and agreed to work with me and support me in this academic endeavor. This project would not have been possible without Jaime's initial interest in my skills, her open mind, her support, and her guidance. I would also like to acknowledge Bethany Hamilton-Jones, Barbara Newman, Karen McCurdy, Sue Adams, and Minsuk Shim. 


\section{TABLE OF CONTENTS}

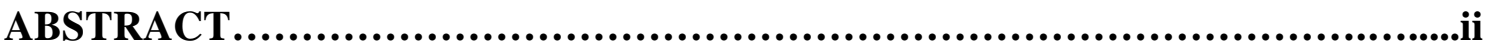

ACKNOWLEDGEMENTS...........................................................

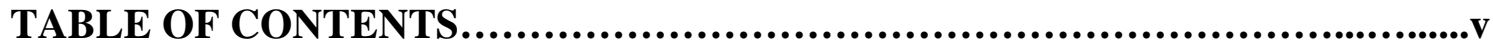

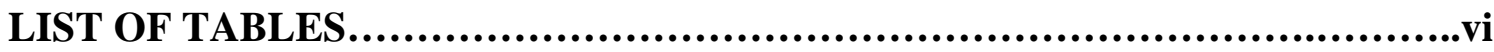

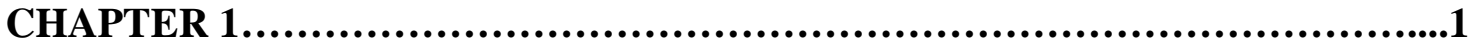

INTRODUCTION

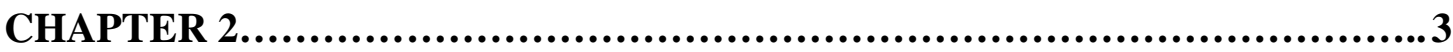

REVIEW OF THE LITERATURE

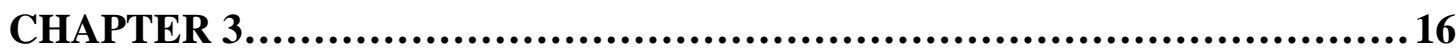

METHODOLOGY

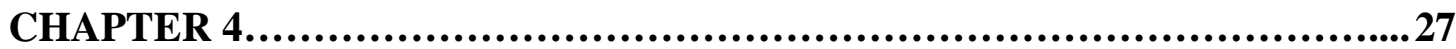

FINDINGS

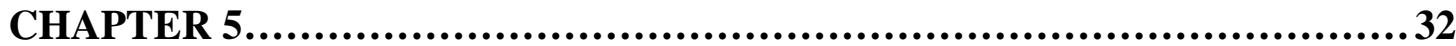

CONCLUSION

APPENDICES.....................................................................48

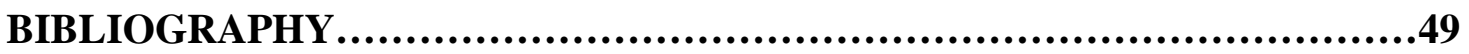




\section{LIST OF TABLES}

TABLE

PAGE

Table 1. Means and Standard Deviations for all Continuous Variables

Table 2. Frequencies and Cumulative Percents of all Categorical Variables

Table 3. Correlations Matrix of all Variables

Table 4. Analysis of Covariance Attachment Classification and Emotional Reg. 44

Table 5. Analysis of Covariance Attachment Classification and Cognitive Reg. 45

Table 6. Analysis of Covariance Attachment Classification and Behavioral Reg. 46

Table 7. Factor Analysis Table of Self-Regulation Items 


\section{CHAPTER 1}

\section{INTRODUCTION}

Infant attachment style predicts concurrent and later socio-emotional functioning in various domains including self-regulation skills (Altamura, 2012; Cassidy, 1994; Waters, Virmani, Thompson, Meyer, Raikes, \& Jochem, 2010). Attachment style is a pattern of interaction that develops between an infant and their caregiver (Bretherton, 1992; Calkins \& Leerkes, 2004). Self-regulation is the ability to control and inhibit impulses, direct attention, and modulate emotions (Crugnola, Tambelli, Spinelli, Gazzotti, Caprin, \& Albizzati, 2011; McClelland, 2010; Panfile, \& Laible, 2012; Zimmerman \& Schunk, 2001). It therefore includes behavioral, cognitive, and emotional aspects. At preschool age, this includes a child's deliberate attempt to modulate, modify, or inhibit one's actions and reactions toward a more adaptive end (McClelland, Ponitz, Messersmith, \& Tominey, 2010). One component of self-regulation, emotional regulation is the awareness, modulation of, and regulation of emotions in productive ways (Denham, Bassett, Way, Mincic, Zinsser, \& Graling, 2012). Literature supports a relationship between attachment style and emotional regulation (Panfile \& Laible, 2012; Waters, 2010; Mikulincer, 2005; Cassidy, 1994). Research also indicates that emotional regulation is linked to cognitive and behavioral regulation (Garner \& Waajid, 2012; Denham, 2012; Tarullo, Obradovic, \& Gunnar, 2009; Romani, 2010; Smith-Donald, 2007). However, existing literature surrounding attachment theory and various components of self-regulation is limited. The paucity of information available and lack 
of consensus about the definition of cognitive and behavioral regulation make them difficult constructs to examine. Furthermore, the relationship between attachment status and its link to behavioral and cognitive self-regulation abilities has never been studied in depth.

The connection between attachment status and emotional regulation calls for more research to determine whether securely attached children exhibit high cognitive and behavioral regulation skills as well in comparison to insecurely attached children. This study will examine the predictive relationship between insecure avoidant, insecure ambivalent and secure types of attachment status and each of the components of selfregulation (emotional, behavioral, and cognitive). 


\section{CHAPTER 2}

\section{LITERATURE REVIEW}

The implications of self-regulation skills in preschool are extensive. The ability to self regulate influences academic achievement and learning because attentional focus, behavior inhibition, and sociability constitute standards in the preschool classroom (Drake, Belsky, \& Fearon, 2013). The connection between early attachment relationships and the ability to engage productively with the environment makes attachment a considerable construct for basic research on the developmental antecedents of selfregulation skills needed for the classroom (Drake et al., 2013). Teachers have identified following directions and attentional control issues as primary reasons why children experience difficulties in kindergarten (Blair \& Diamond, 2008). In some parts of the United States, expulsion rates for preschoolers can reach 1 out of every 40 who are enrolled due to behavioral management issues (Blair \& Diamond, 2008). A nationally representative sample of public preschool programs reported nearly $20 \%$ of teachers having expelled more than one student over a 12-month period (Blair \& Diamond, 2008). Factors that disrupt a child's developing abilities to regulate behavior and attention in preschool pose significant problems for adjustment such as following directions, controlling attention, being able to communicate effectively, and sensitivity to others feelings (Blair \& Diamond, 2008). Although preschool children are not expected to have full mastery over these skills by age 4 , there has been a substantial increase in the prescribed medication of psychotropic drugs to children under the age of 5 (Blair \& 
Diamond, 2008). The idea that we are medicating our preschoolers to control their behavior poses a complex question as to how we are approaching early indicators of selfregulatory problems before Kindergarten.

A better understanding of the role of attachment relationships in the formation of self-regulation could provide childhood educators with the necessary information to approach self-regulation issues on a case by case basis. Although attachment is not malleable beyond age 3 , teachers may be able to produce more effective responses to problem behaviors with this information in mind. Viewing children as a by-product of their attachment bond and understanding the implications of this relationship for classroom behavior can help teachers make better informed decisions about handling challenging behaviors in preschool. It may also make them feel better equipped to understand why preschoolers act out in different ways, and can assist them in forming more valid and effective solutions that are efficient and effective.

Research has identified self-regulation as an important aspect of goal attainment throughout the life span (McClelland \& Cameron, 2012). It is one of the components that allow us to effectively meet our short and long-term goals and it contributes to our ability to plan ahead, set strategies, and direct our intentions to achieve long term goals (McClelland \& Cameron, 2012). Self-regulation is one of the most salient predictors of school readiness (Blair, 2008; Tarullo, et al., 2009; Ramani et al., 2010). Dimensions of self-regulation have been found to predict not only academic achievement, but social competence and behavioral conduct problems (Ramani et al., 2010; Tarullo, et al., 2009; Schultz, Izard, Ackerman, \& Youngstrom, 2001). Child outcomes that are associated with psychopathology (i.e. conduct disorders, attentional disorders) have been linked to 
early self-regulation problems such as impulse control and delay of gratification (Schultz et al., 2001). Preschoolers' self-regulation allows for autonomy and social competence that buffers against resulting distress of challenging experiences in the elementary school years (Zahn-Waxler, Klimes-Dougan, \& Slattery, 2000). Research indicates that children who are able to manage their affect, behavior, and attention are also more able to manage challenges faced during peer interactions in elementary years (Tarullo, et al., 2009; Ramani et al., 2010). Self-regulation has been identified as a mediating factor between stress and negative health problems during adolescence (Kadzikowska-Wrzosek, 2012).

Recent research supports the relationship between infant attachment style and emotional regulation competencies that influence the development of self-regulation skills in preschool and kindergarten (Crugnola et al., 2011; Kidwell, Young, Hinkle, Ratcliff, Marcum, \& Martin, 2010; Panfile, 2012; Denham, et al., 2012). The development of self-regulation begins at the same time the initial attachment bond is forming during infancy (Kopp, 1982). However, despite our current knowledge about the important role of self-regulation, little research has been done to understand the role of attachment and its relationship to the development of cognitive and behavioral regulation. Denham and colleagues (2012) propose that emotional regulation may function as a precursor to cognitive and behavioral. She found that children who were better able to regulate their emotions were also better able to remain positive during a challenging task. Dimensions of executive functioning including memory, inhibition, and attention are achieved when a child is best able to monitor and regulate their emotional states (Denham, Bassett, Way, Mincic, Zinsser, \& Graling, 2012). Using a hierarchal regression method, Garner and Waajid (2012) discovered that positive emotionality, attentional 
control, and cognitive competence among preschoolers predicted greater competency to work through challenging tasks (Garner \& Waajid, 2012). Children with these competencies also reported less behavioral outbursts. These findings suggest that children who are better able to regulate their emotions have an easier time with cognitive challenges. Smith-Donald and colleagues (2007) cite a similar predictive relationship between emotional awareness or control and ability to maintain cognitive efforts or inhibit impulses. These authors hypothesize that this type of regulation precedes cognitive and behavioral skills including inhibitory control and following instructions (Smith-Donald et al., 2007; Denham et al., 2012).

\section{Self-Regulation Structure and Research}

Research indicates that self-regulation is a developmental capacity that is initially supported through external sources such as interactions with the primary caregiver during infancy such as rocking, soothing, and pacifying (Calkins \& Leerkes, 2004; McClelland, 2010; Kopp, 1982). Self-regulatory capacities emerge as early as two months evidenced through neurophysiological modulation of arousal states (Kopp, 1982). Then, selfregulation slowly becomes an individual skill that continues to mature during toddlerhood with the onset of voluntary control (Calkins \& Leerkes, 2004; McClelland, 2010; Blair \& Diamond, 2008). Although there is general consensus about the emotional aspect of self-regulation, researchers disagree on which developmental constructs qualify as "behavioral" and which ones qualify as "cognitive" self-regulation.

Emotional regulation is the ability to monitor and adjust the intensity of an emotional experience in order to cope with affective situations (Panfile \& Laible, 2012). Infant strategies used for emotional regulation include looking away from a stressful 
stimulus (i.e. a mother's expressionless face), manipulating body parts (sucking on fingers or toes), or crying to provoke comfort from the caregiver (Crugnola et al., 2011). In toddlerhood, emotional regulation has generally been qualitatively measured by a child's ability to express and modulate their own emotions, engage in prosocial behavior towards others, and remain positive through challenging tasks (Garner \& Waajid, 2012; Mikulincer, 2003; Panfile \& Laible, 2012; Cassidy, 1994; Crugnola et al., 2011).

According to Zimmerman and Schunk (2001), cognitive regulation involves strategies and processes that are utilized to gain success over a particular task (Zimmerman \& Schunk, 2001). Others have noted that performance, forethought, and self-reflection are three important components of cognitive regulation (McClelland, 2010). Liew (2012) used a logical interpretation of both cognitive regulation and behavioral regulation by contrasting between effortful control and executive functions (Liew, 2012). Effortful control is described as a temperament-based behavioral measure such as voluntary control over behavioral inhibition and activation (Liew, 2012). Cognitive regulation is a neurological measure of executive functioning that is conceptualized as goal-directed thoughts deliberately engaged in using attentional shifting, cognitive flexibility and working memory (Liew, 2012). Behavioral regulation can be measured by observing how children act and their ability to control their physical bodies or control aggressive impulses. Cognitive regulation can be measured through attentional tasks. Although Liew notes sociability and emotions as important aspects of self-regulation, he does not discuss them as separate constructs from cognition and behavior. For intents and purposes of this research, the study design will adopt Liew's interpretation of cognitive and behavioral self-regulation. 


\section{Attachment Theory and Research}

Attachment security refers to the interactions between infant and caregiver that foster a child's feelings of competence and skills to initiate environmental and interpersonal exploration (Ainsworth, Blehar, Waters, \& Wall, 1978; Bretherton, 1992). The human attachment system is an innate evolutionary function of development that involves responding to danger and threats in the most adaptive way possible including proximity seeking strategies, identifying with one's caregiver, and reflexes that reinforce the attachment bond such as rooting, grasping, and smiling. Attachment theory proposes that proximity seeking serves as a foundation for a child's feelings of self-worth and ability to rely on the responsiveness of others. Over time, children form cognitive representations of their caregivers and themselves that influence their development (Bretherton, 1992).

A secure attachment develops when a caregiver consistently responds to their young's need for food, safety, protection from danger, and emotional comfort in times of distress (Cassidy, 1994). Infants are born with the biological (innate) need for proximity seeking and ability to express attachment related behaviors for the purpose of provoking care giving responses that will foster a secure attachment. These behaviors include crying, smiling, clinging, and reaching out their arms. In infancy close attachment behaviors with the primary caregiver influence internalized representations of the self and others (Bretherton, 1992). During this time, an infant learns to differentiate self from other through responsive interactions with the caregiver (Kinniburgh, Blaustein, Spinazzola, \& Van der Kolk, 2005; Mikulincer, 1995).

With increasing mobility in toddlerhood, attachment manifests differently as 
children control and maintain close proximity to their caregiver by crawling, walking, and climbing toward them. During this period of development, it is normal for children to become upset during departure from their caregiver, who is a "secure base" from which the child can explore on his own and return when feeling distressed.

When an infant's need for security is not met by their primary caregiver such as in the instance of abuse and/or neglect, they use secondary strategies for calming themselves during distress or worry (Bretherton, 1992). In these instances, an insecure attachment forms. Insecurely attached infants experience a different developmental trajectory than their secure counterparts. Mary Ainsworth identified two sub-types of insecure attachment based on particular behavior patterns displayed by children around age 2 and labeled them Insecure-Avoidant and Insecure-Ambivalent attachment styles (Ainsworth et al., 1978). These children display different behaviors when separated from their caregivers that may range from extreme discomfort and panic to apathy or disorientation (Bretherton, 1992). Insecure attachment patterns emerge as a result of early care giving experiences. Infants learn to modulate their emotions with support from their caregiver's voice, facial expressions, and gestures (Crugnola et al., 2011). Avoidantattachment occurs commonly when abuse or neglect occurs on the behalf of the caregiver, and regulation of affect is absent. Avoidant-attached infants typically learn to regulate by simply deactivating their affective system, or learning to function without use of emotion, stemming from instances of rejection by their primary object of affective expression (Crugnola et al., 2011). By contrast, insecure-ambivalent infants adopt a different strategy as a result of their early experiences with their caregiver. It is speculated that infants classified as "ambivalent" have experienced unpredictability by 
their caregiver. An over-activation of their attachment system (I.e. excessive crying and screaming) to gain comforting responses from their caregiver results in hyper-vigilance and a lack of interaction with the surrounding environment (Crugnola et al, 2011). These infants are most commonly the most disturbed, and angry upon separation and reunion with their primary caregiver and may need excessive comfort. Avoidant-attached infants appear aloof and independent, while ambivalent attached infants appear emotional, angry, and clingy.

Drawing from a model which integrates theoretical components of Bowlby's Attachment Theory, (1982), Ainsworth's Strange Situation (1991), and the works of Cassidy and Kobak (1988) as well as Fraley and Shaver (2000), Mikulincer and colleagues (2003) discuss secondary attachment strategies that develop when secure attachment is not a viable option (Mikulincer, Shaver, \& Pereg, 2003). When placed in the strange situation, Insecure-Ambivalent classified children tend to adopt a hyperactivating cognitive strategy. The show distress and are sensitive to behaviors that insinuate rejection or possible abandonment and they are unable to regulate their emotions (Mikulincer et al., 2003). By contrast, deactivating strategies are those which strengthen independence and decrease a child's reliance on others for comfort and soothing (Mikulincer et al., 2003). Using these strategies, Insecure-avoidant infants learn to suppress crying or behaviors that would elicit a response from others because they have deemed them to be useless and tend to be very distant from their caregivers and peers (Mikulincer et al., 2003). These infants are cognitively aware of what is happening around them and are able regulate their emotions only by suppressing them.

The Relationship between Self-Regulation and Attachment 
Research supports the relationship between attachment styles and emotional regulation, a key dimension of self-regulation. Starting in infancy, Kopp (1982) suggests that there is a connection between caregiver sensitivity (a crucial dimension of attachment style) and voluntary sensorimotor regulation (Kopp, 1982). She also suggests that the quality of the caregiver-infant relationship plays a key role in the development of self-initiated regulation skills such as compliance to a request and inhibition of impulses (Kopp, 1982). The implication here is that self-regulation revolves around internal mechanisms that begin to operate and develop in response to a warm, sensitive, and supportive caregiver relationship. This theoretical link is supported with research that examines the internal working model that develops during infancy and has lasting effects. The internal working model is a mental representation that an infant forms about themselves, their caregiver, and the effectiveness of their attempts to gain responses from others (Mikulincer, 1995). Securely attached infants will maintain an internal working model that views themselves as powerful negotiators of their environment and will seek comfort in times of distress (Mikulincer, 1995). Attachment experiences are a primary source for an individual to learn about their own self-image and their ability to have their needs met (Mikulincer, 1995). Self-regulation skills are shaped around these same developmental constructs, suggesting that attachment dynamics are a key component of self-regulation skills.

Further research supports the relationship between attachment styles and emotional regulation. Cassidy (1994) found a distinct connection between child attachment status and patterns of emotional expressiveness (Cassidy, 1994). Crugnola and colleagues recently assessed emotional regulation of infants after classifying their 
attachment status and discovered differences between the attachment groups (Crugnola et al., 2011). Secure attachment is positively related to children's ability to understand and communicate their emotions as well as regulate them. Waters et al. (2010) found that preschoolers are less likely to avoid conversations about negative feelings when they have a secure attachment to a caregiver (Waters et al., 2010).

In contrast, insecurely attached children tend to resort to negative coping strategies when faced with emotionally challenging situations such as dissociation from or avoidance of emotional expression (Braungart, 2001). There is also evidence that mothers of insecurely attached infants use strict methods of control over their children's expression of emotion (Berlin \& Cassidy, 2003). In contrast, secure attachment to a caregiver has been linked to resiliency from traumatic experiences and successful coping strategies for negative feelings (Kinniburgh et al., 2005).

Crugnola et al. (2011) discuss the importance of parental scaffolding of emotional regulation in the first two years of life. In cases of avoidant attachment, when a caregiver does not assist in the modulation of emotions by comforting, soothing, or talking about negative feelings, emotional suppression or deactivation is promoted out of child's attempt to defend themselves from future rejection (Crugnola et al., 2011). Although it may appear that this child displays excellent emotional regulation skills, research suggests otherwise. Laboratory studies that measure physiological responses to stress in the hypothalamic-pituitary-adreno-cortical axis indicate that these infants experience a heightened response; increased heart rates and cortisol levels, indicating that they are experiencing these feelings internally (Diamond, \& Fagundes, 2010). However, Insecureavoidant attached infants are unique in their ability to self-soothe, which may foster their 
ability to attain high behavioral regulation skills (Crugnola et al., 2011). Alternatively, Insecure-ambivalent children have a heightened sense of fear about exploring their environment, and some literature suggests that these infants may appear more behaviorally inhibited than Insecure-avoidant children (Cassidy, 1994). Mixed findings conclude that ambivalent children experience low amounts of confidence and assertiveness with their peers in the preschool classroom, limiting their peer interaction and in some cases, a dependent and helpless attitude develops (Cassidy, 1994). These infants are passive with their environment and the people in it, suggesting that they may experience the least amount of emotional, cognitive, and behavioral regulation skills in preschool.

Studies of attachment in adults can also inform our understanding of the relationship between attachment and self-regulation. In a study involving an adult population, Kohn (2012) discovered that Insecure-avoidant attached persons have limited self-regulation capacities because of their cognitive devotion to keeping their attachment system deactivated (suppressing negative memories) (Kohn, 2012). Little information is available concerning the behavior profiles of Insecure-ambivalent children, except their inability to functionally express and regulate their intense emotions, however similar patterns could emerge for these infants as well (Panfile \& Laible, 2012; Mikulincer, 2005; Crugnola et al., 2011).

Because Insecure-avoidant and Insecure-ambivalent infants exhibit such a unique pattern of emotional development, research is needed to describe the relationship between attachment status and behavioral regulation as well as cognitive regulation in order to provide a comprehensive picture of regulation factors for preschool aged 
children. The early caregiver relationship is a powerful influence in childhood development, and infant attachment style is stable (unchangeable) after age 3. Preschool aged children have a solidified internal working model and attachment style that influences their ability to self regulate in the classroom. An important determining factor for school readiness is children's ability to regulate their behavior, attention, and emotions in order to demonstrate competence in interpersonal and academic areas (Blair \& Diamond, 2008; Tarullo, et al., 2009). The only study relating attachment to cognitive or behavioral self-regulation specifically was by Kochanska (2009) who made a distinct connection between insecure attachment status and performance on a behavioral task that involved inhibiting impulses in response to stimulation (Kochanska, 2009). The laboratory task evaluated 89 preschoolers' ability to inhibit their impulses and focus their attention elsewhere. This challenge could be considered behavioral or cognitive. Results indicated that attachment status was related to the ability to regulate their behavioral impulses with mediation by a particular genetic contribution, suggesting that biology interacts with attachment style to affect self-regulation.

\section{Hypotheses}

Considering the existing literature surrounding self-regulation and attachment styles, it is plausible to hypothesize that securely attached infants are best able to achieve high levels of emotional, cognitive, and behavioral regulation at preschool age.

H1: Securely attached infants will exhibit highest levels of emotional, cognitive, and behavioral regulation at preschool age when compared to their insecure-avoidant and insecure-ambivalent counterparts.

Insecure-avoidant infants may have a harder time achieving emotional and cognitive 
regulation when compared to their secure counterparts because of their constant preoccupation with fear of social rejection, but behavioral regulation may be high as they have learned to resist efforts to connect with their environment as well as internalize their needs for comfort and attention.

H2: Insecure-avoidant attached preschoolers will exhibit low levels of emotional and cognitive regulation, but high levels of behavioral regulation when compared to their secure counterparts.

Finally, because of their hyperactivated attachment system, Insecure-Ambivalent infants may have lowest levels of emotional, cognitive, and behavioral regulation when compared to their secure and avoidant counterparts. These infants are least able to modulate their emotions and are in constant need of reassurance of their safety while also fighting for independence, and they may have great difficulty in their ability to focus, inhibit their impulses, and remain engaged in long-term attentional tasks.

H3: Insecure-ambivalent preschoolers will exhibit lowest levels of emotional, cognitive, and behavioral regulation when compared to their secure counterparts. 


\section{CHAPTER 3}

\section{METHODOLOGY}

Procedures and Sampling

This study examined the relationship between attachment status and selfregulation at preschool age by analyzing data from the Early Childhood Longitudinal Study -Birth Cohort (ECLS-B). This dataset is a large-scale, nationally representative sample of children born in 2001 in the United States. The Early Childhood Longitudinal Study-Birth Cohort is the most recent longitudinal data set that captures socio-emotional as well as physical development in a variety of caregiver settings for young children (Kotelchuck, 2009; Paulson, Keefe, \& Leiferman, 2009; Sparks, 2009). The data are intended to provide information about developmental patterns and school readiness for American youth. Multidimensional evaluations were completed in four waves: 9 months, 2 years, preschool, and entry to kindergarten (Andreassen \& West, 2007). Data were collected directly from children, by parent-report, by interview, and by early care provider report. The ECLS-B research used a specific complex sampling procedure which involved cluster sampling (Najarian, Snow, Lennon, Kinsey, \& Mulligan, 2010). Cluster sampling involves dividing the population into homogenous groups, and sampling from each group. This type of sampling is probabilistic, meaning all people within the population have equal chance of becoming part of the sample. Preschool wave data is not representative of all preschoolers in general, but of children born in the year 2001 who were age 4 (preschool age) at the time of data collection (Najarian, et al., 
2010). For this study, I will use data from the age 2 and preschool (age 4) waves.

The sample for the preschool wave included a total sample size of 8,900 children $54 \%$ of whom were White-Non Hispanic, 14\% Black, 25\% Hispanic, 3\% Asian/Pacific Islander, and 4\% Other Non-Hispanic. Age range for this cohort included mainly children between the ages of 50 and 56 months (56\%) while $16 \%$ were less than 48 months, $14 \%$ were between 48 and 49 months, and 14\% were 57 months or more. Average maternal education level at the time of the interview was High School Diploma, GED, or some college either vocational or technical. The sample included $75 \%$ living at or above the poverty line and $25 \%$ below. Finally, $82 \%$ of children primarily spoke English at home. (National Center for Education Statistics, n.d.).

\section{Attachment Classification}

Attachment was measured using the Toddler Attachment Sort-45 (Bimler \& Kirkland, 2002; Kirkland, Bimler, Drawneek, McKim, Schölmerich, \& Axel, 2004). The Toddler Attachment Sort (TAS-45) is an abbreviated version of the 100 item Attachment Q-sort (Waters \& Deane, 1985) and contains 39 items. It was adapted for data collection by John Kirkland and Bimler of the ECLS-B research team to reduce the number of items needed to determine an attachment classification (Andreassen, 2007; Fletcher, \& Park, 2006; Andreassen \& West, 2007). The procedure takes 10 minutes. Researchers observe children interacting with their caregivers during a home visit and rate particular behavior patterns to evaluate affective response to various stimulation and social cues (Waters \& Deane, 1985). The Q-sort items describe behavior patterns, which are sorted into piles repeatedly until a classification of attachment type is specified.

To measure attachment using the TAS- 45 instrument researchers used the Method 
of Successive Sorts. This process involves sorting the 39 attachment items first into two piles (applies vs. not applies), and then sorting into 5 different piles, which constitute a spectrum ranging from "applies most" to "applies least" and "undecided". The TAS-45 was completed by a parent in some cases, and by the interviewer in other cases, and in many cases by both ( $98 \%$ of cases received a TAS- 45 by interviewer after home visit and $74 \%$ of cases included a parent TAS- 45 completion during the visit). Because a higher percentage of cases had a completed TAS- 45 by a trained interviewer, and also because the interviewer was a more reliable instrument, I will use the TAS- 45 completed by the interviewer. Children were classified into 3 main categories; A) Avoidant, B) Secure, and C) Ambivalent. The TAS-45 has been found to maintain construct validity, meaning it accurately measures attachment and no other psychological or developmental phenomena (Spieker, Nelson, \& Condon, 2011).

Approximately between 60 and $70 \%$ of the United States population is classified as securely attached, while $20-25 \%$ are classified as avoidant, and $10-15 \%$ as ambivalent (Ainsworth, 1978). The TAS-45 measurement for attachment used in the ECLS-B dataset reflects these norms $(\mathrm{A}=28 \% ; \mathrm{B}=58 \%$; $\mathrm{C}=14 \%)$ for the overall sample of children for whom an attachment status was gathered (Andreassen \& West, 2007). Benefits of the TAS-45 include a natural setting which allows for more detail and observations about a child's sociability despite attachment. Finally, the Q-sort method is the preferred method for longitudinal research because of its non-invasive nature and prevents instrument decay over time and children may habituate to the Strange Situation Procedure (Ijzendoorn, Vereijken, Bakermans-Kranenburg, \& Riksen-Walraven, 2004). Self-Regulation 
Self-regulation was measured through interviews and questionnaires completed by parents and early care and education providers. Only early care and education provider ratings will be used for this study as parents' opinion is not always objective and may bias the data. Specifically, self-regulation at preschool age was measured in caregiver interviews that incorporated elements of socio-emotional development in the context of the environment (Najarian, Snow, Lennon, Kinsey, \& Mulligan, 2010). The interviewer asked early care and education providers to rate children on 21 items related to prosocial skills, learning behaviors, temperament, problem solving, affect knowledge, and regulation of negative emotions (Najarian, et al., 2010). The interview was developed by referencing an abbreviated version of the Preschool and kindergarten Behavior Scales (PKBS-2) (Merrell, 2003) and the Social Skills Rating Scale (SSRS) (Gresham \& Elliot, 1990). Both the PBKS-2 and the SSRS were selected as appropriate instruments to guide the Early Care and Education Provider interview questions as they are recognized as strong instruments for evaluating socio-emotional constructs (Najarian et al., 2010). The items on the PKBS-2 scale were developed by a panel of child development experts. Factor analyses revealed that they measured externalizing and internalizing problems. Construct validity of the PKBS-2 has been demonstrated in smaller samples of preschool children (Edwards, Whiteside-Mansell, Conners, \& Deere, 2003) and it has been found to have moderate to high interrater reliability (Edwards et al., 2003). Furthermore, Merrell (1995) concluded that PKBS-2 was found to illustrate appropriate convergent and construct validity for measurements of social skills and externalizing/internalizing problems when compared to other assessments including the SSRS used in the ECLS-B research (Merrell, 1995). The SSRS was designed specifically for the ECLS-B study 
(Najarian, et al., 2010). Elliot and colleagues (1998) found the SSRS to have high testretest reliability in a 6 week follow-up period, high interrater reliability, and to maintain internal consistency (Elliot, Gresham, Freeman, \& McCloskey, 1988). Construct validity of the SSRS was also confirmed with comparison to the Revised Behavior Problems Checklist and Teacher Ratings of Academic Performance (Elliot, et al, 1988). However, more recent evaluations of the SSRS have found the instrument to have low convergent validity between teachers and peers, while also indicating that future modifications of the SSRS should address the bipolar relationship between its two constructs (Social Skills and Problem Behaviors) that load in opposite directions on its main construct, social competence (Fantuzzo, Manz, \& McDermott, 1998).

A trained interviewer inquired about how often the care provider witnessed a child behaving in particular ways within the previous three months and rated their answers on a Likert scale from 0 (never), 1 (rarely), 2 (sometimes), 3 (often), to 4 (very often) (Najarian, et al., 2010). There were a total of 21 self-regulation items to measure each child's individual functioning. These items ranged from social components such as "accepted by other children", "disrupts" or "annoys" others, and "physical aggression" to individually focused items such as "keeps working until finished", "seems unhappy", and “worries about things.” Dice, Shim, Hamilton-Jones, and Hicks (unpublished manuscript) conducted a factor analysis and found that self-regulation is composed of four factors including Factor 1 Externalizing Negativity, Factor 2 Sociability, Factor 3 Attention, and Factor 4 Internalizing Negativity. These factors capture the different aspects of self-regulation measured by the ECLS-B preschool wave caregiver psychometric reports. For this study design, each factor will be included to determine 
whether attachment status is predictive of self-regulation reports at preschool age. Factor 1, Externalizing Negativity, includes eight items that assess a child's behavioral control. Factor 2, Sociability, includes four items to capture how a child's actions and behaviors toward other children in the classroom. Factors 1 and 2 are both measures of behavioral regulation. Factor 3, Attention, includes five items loaded on child's ability to work and stay on Finally, Factor 4, Intrinsic Negativity, includes items to assess how often a child appears worried or unhappy.

For this particular study design, Factors 1,2 and 3 are especially relevant.

Although research has provided empirical support for the connection between attachment status and emotional regulation (sociability and internalizing negativity), there is little evidence for the relationship between attachment status and elements of self-regulation that are not particularly emotional (i.e. impulsivity, aggression, attention).

\section{Procedures}

All data were variables contained in the Early Childhood Longitudinal StudyBirth Cohort. The required variables for this particular analysis were extracted and analyzed using SPSS (Statistical Package for the Social Sciences). Children with mental retardation, Autism, and very low birth weight were excluded from the sample. Variables included in the data set were child gender, race, and birth weight (moderately low, normal), a socioeconomic status indicator variable, toddler attachment status, and 11 selfregulation items from the Early Care and Education Provider interview.

First, cases with response codes that were "Not applicable", "Data Suppressed", "Don't know", "Refused" and "Not Ascertained" were assigned a system missing value ( a [.] in SPSS). Some self-regulation items were also reverse coded to maintain a proper 
scale for 'high' versus 'low' self-regulation. Thus, self-regulation variables that included aggression, annoys others, has temper tantrums, and has difficulty concentrating were reverse coded in order for high scores to be coded as low regulation and low scores to be coded as high regulation.

In order to account for missing data, a couple of considerations were taken into account. First, the maximum amount of cases to be used were those who were not missing a toddler attachment status indication and were not assigned a Disorganized attached status. Imputing an attachment status was not an option as this would severely skew the data and Disorganized attachment status was not included in this analyses. Cases with missing attachment information or with Disorganized attachment were deleted list wise, meaning they were completely deleted from the dataset. The dependent variable, self-regulation, also contained several cases of missing information. Simple frequency analyses revealed that those who were missing self-regulation information were missing about 4 out of the 11 items. Two options were available for dealing with missing self-regulation item responses. There is the option to completely delete all cases with missing self-regulation data. However, there is the possibility that these cases are those whom had extremely low levels of self-regulation and the interviewer was unable to report their behavior. Deleting these cases could exclude a particularly important part of the sample population; those with low self-regulation. A cross-tabulations analysis between the self-regulation items and attachment classification revealed that those with insecure attachment were indeed those who were also missing self-regulation items. Therefore, it was decided to impute scores for those who were missing self-regulation data. A Multiple Imputations function was conducted in which the computer uses an 
algorithm method to impute a value for a particular case 5 times. An average or "pooled" number is then calculated and a new dataset is created with pooled imputations. Multiple Imputation method is not random; the methodology involves imputing a number that takes into account other cases within the dataset that share similar values across domains, and imputes an average of 5 possible values.

After the self-regulation items were imputed and each case had no missing values, categories of self-regulation were constructed using the 11 items and dividing them into three categories, "emotional regulation", "cognitive regulation", and "behavior regulation". In order to determine the strength of the relationship between three types of self-regulation, each individual case had to be assigned an emotional regulation score, a behavioral regulation score, and a cognitive regulation score. This was determined by grouping together self-regulation items that loaded together, deciding which type of regulation they were most descriptive of, and then averaging the items' response rating. Each of the 11 self-regulation items were placed in a factor analysis to determine which items loaded together. Results of the factor analysis indicated that "Aggressive", "Temper Tantrums", "Annoys Others", and "Impulsivity" loaded onto one factor that was labeled "Externalizing Negativity." These items constitute the Behavioral Regulation portion of this analysis. Next, "Pays Attention", and "Has difficulty concentrating" loaded together and constitute Cognitive Regulation for this analysis. Finally, items "Makes friends easily", "Understand others", and "Comforts others" loaded together and will be used for Emotional Regulation for this analysis. Using the factor analysis as a guide, items including annoys other children, acts impulsively, and has temper tantrums were averaged and recoded into a different variable called "behavioral regulation." The 
same process was used with items makes friends easily, is accepted by other children, tries to understands others, and comforts others. Scores were averaged and recoded into a variable called "emotional regulation." Finally, has difficulty concentrating and keeps working until finished scores were averaged and recoded into a different variable called “cognitive regulation.” A Bivariate correlation analysis determined that Emotional Regulation (tries to understand others, comforts others, and makes friends easily), Behavioral Regulation (aggressive, impulsive, annoys others, and temper tantrums), and Cognitive Regulation (difficulty concentrating, pays attention well) are significantly related to one another with the strong correlations residing between cognitive regulation and behavioral regulation $(\mathrm{r}=.55, \mathrm{p}=.000)$, and between emotional regulation and cognitive regulation $(\mathrm{r}=.37, \mathrm{p}=.000)$.

The final sample contained 2,650( $n=2,650)$ children after excluding cases with Mental Retardation, Autism, extremely low birth weight, and those with missing attachment classification data. Because the Early Childhood Longitudinal Birth Cohort Study used a complex sampling procedure that over-sampled low birth weight and minority children, the sample is not random and thus needed to be weighted to adjust for the sampling procedures. In order to make this research project's particular sample representative of the United States population, a normalized weight was used to produce a more accurate Standard Error (SE) and adjust the sampling distribution. The smallest amount of Standard Error is the most precise, and is therefore the goal of using a weighted sample. In order to accomplish this process SPPS, the Approximation Method was used. This method involved first normalizing the weight and then adjusting for the complex design using design effects (DEFF). A particular weight is chosen by taking into 
account the wave and source of the data being adjusted. This research design used data from the 2-year and Preschool Age waves. Sources included the Toddler Attachment Sort-45 (TAS-45, 2-year Wave 2) and the Early Care and Education Provider Interview (ECEP, Preschool Age Wave 3). A weight (W33J0) was chosen based on this information and was then inserted into a Normalized Weight formula [W33J0*(sample $\mathrm{n} /$ Population N)]. This produced a weighted sample size of 2,849,850 $(\mathrm{n}=2,849,850)$. Next, adjusting for the complex sampling design was done using the Design Effects (DEFF) which is calculated as the ratio of the Standard Errors Squared divided by the Standard Errors Squared when Simple Random Sampling (SRS) is assumed [SE^2/SE^2 assuming $S R S]$. The reason this procedure was important is because all statistical analyses should be based on Standard Errors that account for the non-random sampling design of the Early Childhood Longitudinal Study.

\section{Descriptive Statistics of the Sample}

Frequencies of child gender, child race, socioeconomic status, race, and toddler attachment classification can be found in Table 1 . The sample had a relatively even distribution of males and females (48.9\% male, $51.1 \%$ female). The most frequently reported child race was White (56\%) followed by Black (14.4\%), Hispanic (15.3\%), Other (4.0\%), Asian (2.4\%), Alaskan/Native American (.5\%), and Hawaiian/Pacific Islander $(.5 \%)$. The socioeconomic status indicator variable was calculated based on income level, parental education, and parental occupation. These factors computed a score for each family that was then placed in a particular quintile. Upon reviewing the distribution of attachment classification among the sample, it is desired for these numbers to match those of the general population (between 60-70\% Secure, 20-25\% Avoidant, 10- 
$15 \%$ as Ambivalent). The frequencies found in this sample approached these numbers with $71 \% \%$ Secure, $18.1 \%$ Avoidant, and 9.9\% Ambivalent. 


\section{CHAPTER 4}

\section{FINDINGS}

\section{Preliminary Analysis}

A Bivariate Correlation analysis (Pearson's r) was used to measure the strength between each of the self-regulation types. See Table 3. The DEFF adjusted weight was applied to all variables and a Bivariate Correlation analysis was used to determine significant relationships between self-regulation items, gender, attachment classification, child race, and socioeconomic status at wave 3 (Preschool Wave) and wave 2 (Two year Wave). Socioeconomic status, measured by a combination of parental income, education, and occupation, at wave two was significantly related to socioeconomic status at wave 3 $(\mathrm{r}=.8, \mathrm{p}<.000)$. The strength of this relationship tells us that SES was generally stable across the two waves (between determining attachment classification and observing selfregulation), thus, it was decided to only use the socioeconomic variable for wave 3 in the main analysis. Another reason for this decision includes the notion that socioeconomic status, if it were to affect the study design, would affect at wave 3 when the dependent variable was collected. For these reasons it was decided to control for socioeconomic status at wave 3 only.

More interestingly, the correlation analysis determined that child race was only significantly related to socioeconomic status $(\mathrm{r}=-.31, \mathrm{p}=<.000)$. Child race was not included in the model for primary analysis because it was not significantly correlated with any of the attachment or self-regulation variables. Gender was significantly related 
to emotional regulation $(\mathrm{r}=.17, \mathrm{p}=.000)$, behavioral regulation $(\mathrm{r}=.17, \mathrm{p}=.000$, and cognitive regulation $(\mathrm{r}=.20, \mathrm{p}=.000)$. Gender approached a significant relationship to attachment classification $(\mathrm{r}=.04, \mathrm{p}=.061)$. It is important to control for gender in the main analysis in order to account for these significant relationships.

The correlation table was also used to determine the strength of the relationship between the three different types of self-regulation. When looking at each of the 11 selfregulation items, significant correlations existed in multiple domains. First, the behavioral regulation items physically aggressive, annoys others, has temper tantrums, and acts impulsively were all strongly correlated with one another. However, physical aggression was the only self-regulation variable to correlate negatively with the other behavioral regulation items. For example, physical aggression was significantly negatively related to impulsivity $(\mathrm{r}=-.47, \mathrm{p}<.000)$ meaning, children were either highly impulsive or highly aggressive, but not both at the same time. The same was true for temper tantrums $(r=-.57, p<.000)$, meaning children were either aggressive, or they were reported to have many temper tantrums. Finally, physical aggression was also significantly negatively related to whether a child annoys other children $(\mathrm{r}=-.62, \mathrm{p}<.000)$. One way of interpreting this is that children were either annoying, or they were physically aggressive, but rarely both. It appeared to be the case that physical aggression may not be a good indicator of self-regulation, indicated by its negatively correlations with other behavioral regulation items. Physical aggression was taken out of the model and was analyzed with attachment status by itself in order to account for any skewness of the behavioral regulation measurement during analysis. Emotional regulation items were also significantly related to one another. As expected, being accepted by other children 
was significantly related to making friends easily $(r=.60, \mathrm{p}<.000)$, and comforts others $(\mathrm{r}=.30, \mathrm{p}<.000)$, and tries to understand others $(\mathrm{r}=.26, \mathrm{p}<.000)$. Making friends easily was also correlated to comforting others $(\mathrm{r}-.39, \mathrm{p}<.000)$ and trying to understand others $(\mathrm{r}=.38, \mathrm{p}<.000)$. More interestingly, these emotional self-regulation items were also moderately correlated to behavioral regulation items with significant correlations between physical aggression $(\mathrm{r}=-.25, \mathrm{p}<.000)$, impulsivity $(\mathrm{r}=.19, \mathrm{p}<.000)$, temper tantrums $(\mathrm{r}=.25, \mathrm{p}<.000)$, and annoying other children $(\mathrm{r}=.25, \mathrm{p}<.000)$. As predicted by Hypothesis 1, behavioral and emotional constructs were significantly related, indicating that these facets of self-regulation are interrelated. Cognitive regulation items also indicated strong correlations with one another. For example difficulty concentrating was significantly related to paying attention well $(\mathrm{r}=.58, \mathrm{p}=.000)$ and keeps working until finished $(\mathrm{r}=.58, \mathrm{p}=.000)$. However, these items were also significantly related to behavioral and emotional regulation items as well. Difficulty concentrating was significantly correlated with physical aggression $(r=-.34, \mathrm{p}<.000)$, impulsivity $(\mathrm{r}=.43<.000)$, annoys other children $(\mathrm{r}=.46, \mathrm{p}=.000)$. Paying attention well was also significantly related to annoying other children $(\mathrm{r}=.42, \mathrm{p}=.000)$, physical aggression $(\mathrm{r}=-$ $.35, \mathrm{p}=.000)$, and temper tantrums $(\mathrm{r}=.28, \mathrm{p}=.000)$. Correlations between emotional and cognitive items were also significant such as acceptance by other children with paying attention well $(\mathrm{r}=.33, \mathrm{p}=.000)$ and trying to understand others with working until finished $(\mathrm{r}=.24, \mathrm{p}=.000)$. These strong correlations reveal that each type of regulation is strongly related to one another and support the hypothesis that self-regulation constructs function individually while also influencing one another.

Moving toward preparation for the main analysis, Analysis of Covariance is a 
statistical test used to determine whether there are any significant differences between the means of two independent groups on a particular measure while also controlling for a third variable. In this case, the independent groups were Securely Attached, Avoidant Attached, and Ambivalent Attached. The ANCOVA determined whether these three groups differed among measures of three types of self-regulation (emotional, behavioral, cognitive) while controlling for Socioeconomic status, race, and gender. Exploratory statistics including histogram plots were displayed in order to determine whether the data met the associated assumptions needed for an ANCOVA analysis. One assumption entails normal distribution of the dependent variable. The plots indicated that some of the self-regulation measures did not meet this assumption, the most skewed being child aggression. Analysis proceeded by removing child aggression from the primary analysis and running it separately in order to account for its failure to meet normal distribution. To account for the skew in normal distribution, a post hoc option for ANCOVA in which normality is not assumed, Sidak's test, was used. Other variables appeared to have somewhat normal distribution, thus ANCOVA was conducted with this consideration in mind. A second assumption of ANCOVA design indicates homogeneity of variances. Levene's Test of Equality of Error Variances indicated that this assumption was met for emotional regulation $(\mathrm{F}=.214, \mathrm{p}=.807)$, behavioral regulation $(\mathrm{F}=2.106, \mathrm{p}=.122)$, and cognitive regulation $(\mathrm{F}=.500, \mathrm{p}=.606)$.

ANCOVA

Three individual Analyses of Covariance were used to determine whether the relationship between attachment classification and three types of self-regulation are statistically significant. Three individual ANCOVAs were used to determine whether the 
relationship between attachment classification and three types of self-regulation are statistically significant. The first ANCOVA determined mean differences between three attachment groups on measures of emotional regulation when accounting for SES and gender. The model itself was significant $(\mathrm{F}=27.42, \mathrm{p}=.000)$, indicating a relationship between attachment style and emotional self-regulation. Sidak's test indicated a significant relationship between Avoidant and Secure groups (mean difference -.071, $\mathrm{p}=.039$ ), Avoidant and Ambivalent (mean difference .124, $\mathrm{p}=.016$ ), and Ambivalent and Secure (mean difference $-.195, \mathrm{p}=.000$ ).

The second ANCOVA determined mean differences between the three attachment groups on measures of behavioral regulation while controlling for SES and gender. This model was also significant $(\mathrm{F}=23.25, \mathrm{p}=.000)$ indicating a relationship between attachment status and behavioral regulation. Further, a post hoc Sidak's test revealed one pairwise comparisons that was significant. Avoidant and Secure attached children differed significantly on measures of behavioral self-regulation (mean difference -.098, $\mathrm{p}=.017)$. However, there were not significant group differences between Avoidant and Ambivalent attached children or between Ambivalent and Secure children.

The final ANCOVA determined mean differences between the three attachment groups on measures of cognitive regulation while controlling for SES and gender. This model was also significant $(\mathrm{F}=44.84, \mathrm{p}=.000)$. Post hoc Sidak's test revealed through pairwise comparisons determined significant differences between Avoidant and Securely attached children (mean difference -.111, $\mathrm{p}=.006$ ), and the differences between Secure and Ambivalent attached children approached significance (mean difference .098, $\mathrm{p}=.058$ ), but not between Ambivalent and Avoidant attached children. 


\section{CHAPTER 5}

\section{CONCLUSION}

Results indicated findings that were somewhat in support of the proposed hypotheses. As predicted, the bivariate correlation analysis determined that selfregulation items tend to cluster together into emotional/affective, behavioral, and cognitive/attentional groups with strongest correlations between alike items. However, there were substantial correlations between each of these types of self-regulation, meaning that they are interrelated. The overlapping nature of different types of selfregulation suggests that research should broaden the conceptual framework of selfregulation to include each facet.

Hypothesis 1, children with secure attachment will exhibit highest levels of emotional, cognitive, and behavioral regulation was partly confirmed. Securely attached children did exhibit higher levels of emotional regulation when compared to their ambivalent and avoidant counterparts. However, although securely attached children had higher levels of behavioral regulation than their avoidant counterparts, secure attached and ambivalent attached children did not differ on measures of behavioral regulation. Finally, securely attached children exhibited significantly higher cognitive regulation than their avoidant counterparts, but differences between securely attached children and ambivalent attached children only approached significant differences on measures of cognitive regulation.

Hypothesis 2, insecure-avoidant attached preschoolers will exhibit low levels of 
emotional and cognitive regulation, but high levels of behavioral regulation when compared to their secure counterparts was also partly confirmed. Avoidant attached infants did experience lowest levels of cognitive regulation and differed from their secure counterparts significantly. The same was true for emotional regulation when compared to their secure counterparts. However, their behavioral regulation was also low when compared to their secure counterparts. Therefore, avoidant attached children did not exhibit high levels of behavior regulation as predicted, but significantly lower behavioral regulation.

Hypothesis 3, insecure-ambivalent preschoolers will exhibit lowest levels of emotional, cognitive, and behavioral regulation when compared to their secure counterparts, was also partly confirmed. Ambivalent attached children did have the lowest levels of emotional regulation, as they differed from securely attached children while avoidant attached children only differed from their secure counterparts. However, because avoidant attached children exhibited the lowest levels of cognitive regulation, and ambivalent and avoidant children scored similarly on measures of behavioral regulation, the second part of this hypothesis cannot be confirmed.

Depending on attachment style, children may have more difficulty regulating in one area over another. For example, results indicate that Avoidant attached infants had the most difficulty regulating their cognition and behavior, but they did not perform as poorly on measures of emotional regulation as Ambivalent attached infants. This finding reinforces the notion that Avoidant attached infants have learned to control and regulate their emotions from a young age, yet, they struggle to keep up in other domains. These results also indicate that Ambivalent attached infants do not differ from their secure 
counterparts on most measures of self-regulation except emotional regulation skills. As predicted, Ambivalent attached infants have the most difficulty regulating their emotions, yet they maintain self-regulation abilities in other areas. These results also provide support for the idea that a Secure attachment functions as a path towards high selfregulation in preschool.

\section{Practical Implications}

A pressing question is the practicality of this type of research. As has been previously stated, attachment classification may not be malleable beyond toddler years. Therefore, to know and understand attachment's influence on self-regulation is not in order to change a child's attachment type for favorable outcomes. Instead, attachment theory and research should be integrated into higher education curriculum for preschool teachers in order to provide the necessary background in childhood development to engage in age-appropriate scaffolding for self-regulation skills. Attachment style and subsequent internal working models are an integral part of development and function as influential factors for adjustment in early childhood. Not only teachers, but policy makers and education leaders should be aware of the implications of an insecure attachment, its stability, and its relationship with regulation skills in order to foster social competence in early childhood. To be aware of how a child's early bond with their caregiver affects their regulation skills is to understand the many reasons why a child may experience emotional, attentional, and behavioral issues in preschool. This research may open doors to new solutions for reducing the amount of preschool classroom disturbances and expulsions. Furthermore, it may provide insight for interventions for children with low self-regulation skills by using attachment research as a theoretical approach. 


\section{Limitations}

A theoretical limitation of this study involves the notion that the self-regulation variables were recoded into emotional, behavioral, and cognitive self-regulation scores upon results from a preliminary factor analysis and a follow-up correlation analysis. There is no definitive way to interpret the self-regulation items described in the Early Care and Education Provider interview as strictly emotional or cognitive or behavioral as there is significant overlap in the three. Finally, although the Analysis of Covariance did control for child gender and socioeconomic status, there was no way of controlling for the effects of unanticipated extraneous variables, one in particular being age of the child at wave 3 (preschool age). Most developmental research concludes that a "young" 4-year old may act very differently than an "older" 4 year old. Meaning, a child may make great strides in development over the course of several months in preschool. A preschooler who just turned 4 may perform differently than a 4 year old who is about to have a $5^{\text {th }}$ birthday. Unfortunately, an age-in-months variable during Wave 3 data gathering was not available.

Another statistical limitation of this research was the use of multiple imputations to account for missing data. Although SPSS has a systematic method for imputing missing data, it should be understood that this is not the same as using authentic data collected from each person individually. Multiple imputations involves a statistical process that imputes several possible imputations for a particular missing item and then averaging or "pooling" these items for a final imputation. With the amount of missing self-regulation items, this option was the most feasible to continue the analysis.

Finally, a theoretical limitation of this research is the idea that self-regulation can 
indeed be divided into separate components and tested individually. A preliminary factor analysis concluded that the ECLS-B self-regulation items did load in clusters that could be evaluated as groups. To recall, these clusters included Externalizing Negativity, Sociability, Attention, and Prosocial Skills. A further correlation analysis with the same items determined much overlap between all the self-regulation variables, indicating that they are all related to one another. For this research design, alike items that loaded together were relabeled as "behavioral regulation", "cognitive regulation", and "emotional regulation" in order to provide a parallel structure to how these items are labeled in literature. It may be possible that these labels are not the best or most accurate way to interpret self-regulation. A major limitation to this research design is the notion that the items chosen to represent each type of regulation may not necessarily be accurate. Decisions were made based on a comprehensive review of what is known about self-regulation types and their descriptions, however.. There were no follow-up tests to ensure that "emotional regulation" was in fact measuring a child's emotions and not their cognition.

During the preliminary phase of analysis, recoding of the caregiver race variables was attempted. It was identified as an important aspect of the analysis as caregiver race could potentially affect self-regulation rating scores. Similarly, race of the child was intended to be included in the primary analysis. However, child race and caregiver race were not coded the same way in the original ECLS-B data set. Child race was one variable with 7 levels; White, Black, Hispanic, Asian, Pacific Islander, Alaskan/Native American, and Other. Simply including this one variable as a covariate would have sufficed. Caregiver race was not coded this way. Instead, the caregiver was given the 
option to check off as many race categories as they saw fit. Although this freedom allowed the caregiver to identify in the most specific way possible, it disallowed for mutual exclusivity and made recoding the variable into one race variable nearly impossible. Using simple recoding syntax, the choices were recoded to match child race. However, the Hispanic option was defective. After trying numerous times with several different syntaxes, it was decided to not include this variable. An explanation for why the Hispanic race caused a significant problem for recoding was because the caregiver had the option to respond Yes, or No to 'Hispanic', and also identify as either Mexican, Cuban, Puerto Rican, or Hispanic Other. The caregiver could then identify as 'Hispanic' and 'Mexican', however, there was no way of determining how many of the 'Mexican' responses also responded 'yes' to Hispanic versus 'No' to Hispanic. Frequency analysis after attempting to overcome this problem indicated that the number for the Hispanic population would have been extremely low in the sample. It was determined that the reason for this error was a result of the non-mutually exclusive categories in the ECE Provider interview race question. In sum, it is not known through this study whether or not caregiver race influences the relationship between attachment and self-regulation skills in preschool.

\section{Future Research}

Attachment research indicates that children maintain a particular style of social interaction that is an extension of their early care giving experiences (Altamura, 2012; Cassidy, 1994; Bretherton, 1992; Waters et al., 2010). In order to provide the necessary support for positive development, future research should further explore the strength of the relationship between attachment and self-regulation. More importantly, research 
should aim to uncover the cognitive processes that are characteristic of insecureattachment strategies as well as self-regulation skills. This study revealed that insecure attached infants display alternate patterns of self regulation when compared to their secure counterparts. Research that provides more clear and accurate picture of the relationship between these two developmental constructs could pave the way for a smooth transition into preschool and kindergarten for children with attachment difficulties. Teachers' knowledge of attachment beyond its function in infancy may spark a more supportive school environment for children with self regulation difficulties. In order to understand exactly how attachment influences preschoolers' ability to self regulate, more research is needed to uncover the strength of the relationship between the two. 


\section{TABLES}

Table 1

Means and Standard Deviations for all Continuous Variables

\begin{tabular}{lcccc}
\hline \multicolumn{1}{c}{ Variable } & Mean & SD & Min & Max \\
\hline $\begin{array}{l}\text { Emotional } \\
\text { Regulation }\end{array}$ & 3.8669 & .69184 & 1.00 & 5.00 \\
$\begin{array}{l}\text { Behavioral } \\
\text { Regulation }\end{array}$ & 4.0026 & .81264 & 1.00 & 5.00 \\
Cognitive & & & & \\
Regulation & 3.7845 & .81315 & 1.00 & 5.00
\end{tabular}


Table 2

Frequencies and Cumulative Percents of all Categorical Variables

\begin{tabular}{|c|c|c|c|c|}
\hline Variable & Frequency & Percent & $\begin{array}{l}\text { Valid } \\
\text { Percent }\end{array}$ & $\begin{array}{l}\text { Cumulative } \\
\text { Percent }\end{array}$ \\
\hline \multicolumn{5}{|l|}{ Child Race } \\
\hline White & 2010 & 54 & 54 & 54 \\
\hline Black & 520 & 14 & 14 & 68 \\
\hline Hispanic & 550 & 25 & 25 & 93 \\
\hline Asian & 90 & 2 & 2 & 95 \\
\hline Pacf Isl/Hawaii & 10 & 1 & 1 & 96 \\
\hline Other & 140 & 4 & 4 & 100 \\
\hline Total & 3590 & 99.7 & 100.00 & 100.00 \\
\hline \multicolumn{5}{|l|}{$\begin{array}{c}\text { Attachment } \\
\text { Classification }\end{array}$} \\
\hline Avoidant & 550 & 15.4 & 15.9 & 15.9 \\
\hline Secure & 2160 & 59.9 & 61.9 & 77.8 \\
\hline Ambivalent & 300 & 8.5 & 8.8 & 86.5 \\
\hline Disorganized & 470 & 13.0 & 13.5 & 100.00 \\
\hline Total & 3480 & 96.7 & 100.00 & 100.00 \\
\hline
\end{tabular}




\begin{tabular}{ccccc}
\hline SES & & & & \\
\hline Quintile 1 & 420 & 15.9 & 15.9 & 15.9 \\
Quintile 2 & 470 & 17.6 & 17.6 & 33.5 \\
Quintile 3 & 540 & 20.5 & 20.5 & 54.0 \\
Quintile 4 & 580 & 22.0 & 22.0 & 76.0 \\
Quintile 5 & 640 & 24.0 & 24.0 & 100.00 \\
Total & 2650 & 100.00 & 100.00 & 100.00 \\
\hline
\end{tabular}


Table 3.

\section{Correlations Matrix of all Variables}

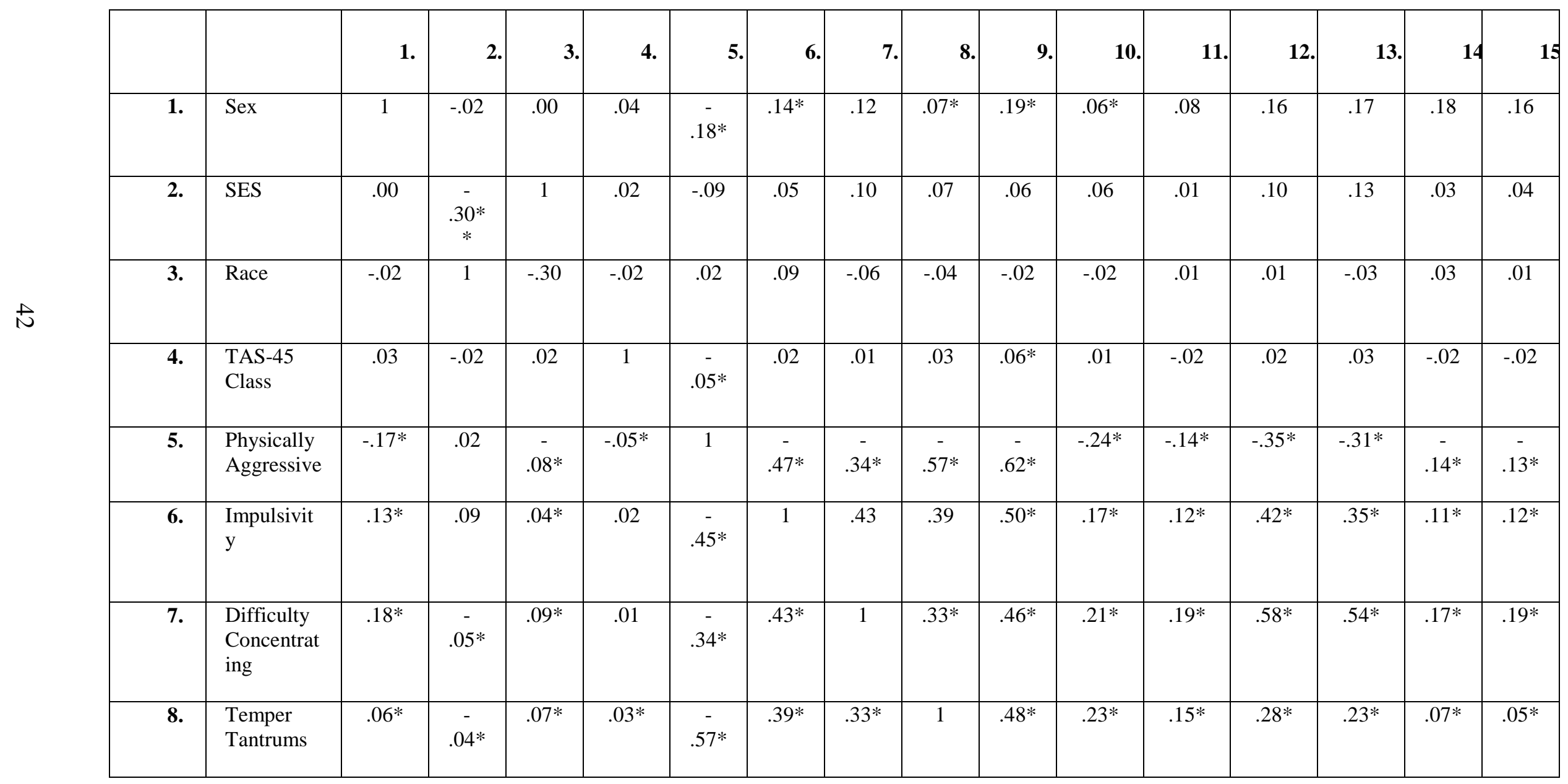




\begin{tabular}{|c|c|c|c|c|c|c|c|c|c|c|c|c|c|c|c|c|}
\hline 9. & $\begin{array}{l}\text { Annoys } \\
\text { Others }\end{array}$ & $.19^{*}$ & -.02 & $.06^{*}$ & $.06^{*}$ & 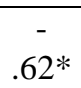 & $.51^{*}$ & $.46^{*}$ & $.48^{*}$ & 1 & $.24 *$ & $.16^{*}$ & $.42 *$ & $.36^{*}$ & $.16^{*}$ & $.15^{*}$ \\
\hline 10. & $\begin{array}{l}\text { Accepted } \\
\text { by Others }\end{array}$ & $.06^{*}$ & $\begin{array}{l}- \\
.02 *\end{array}$ & $.06^{*}$ & .01 & -.23 & $.17 *$ & $.21 *$ & $.23 *$ & $.24 *$ & 1 & $.60 *$ & $.33 *$ & $.28^{*}$ & $.30^{*}$ & $.26^{*}$ \\
\hline 11. & $\begin{array}{l}\text { Makes } \\
\text { Friends } \\
\text { Easily }\end{array}$ & $.08^{*}$ & .01 & .01 & -.02 & $\begin{array}{l}- \\
.14 *\end{array}$ & $.12 *$ & $.19^{*}$ & $.15^{*}$ & $.16^{*}$ & $.60^{*}$ & 1 & $.30 *$ & $.23^{*}$ & $.38^{*}$ & $.37 *$ \\
\hline 12. & $\begin{array}{l}\text { Pays } \\
\text { Attention } \\
\text { Well }\end{array}$ & $.16^{*}$ & .09 & $.10 *$ & .02 & $.35^{*}$ & $.42 *$ & $.58^{*}$ & $.28 *$ & $.42 *$ & $.33^{*}$ & $.29 *$ & 1 & $.58^{*}$ & $.29 *$ & $.29 *$ \\
\hline 13. & $\begin{array}{l}\text { Keeps } \\
\text { Working } \\
\text { Until } \\
\text { Finished } \\
\end{array}$ & $.16^{*}$ & -.03 & $.13^{*}$ & $.03 *$ & $.31^{*}$ & $.35^{*}$ & $.53^{*}$ & $.27 *$ & $.36^{*}$ & $.28 *$ & $.22 *$ & $.58 *$ & 1 & $.23^{*}$ & $.24 *$ \\
\hline 14. & $\begin{array}{l}\text { Comforts } \\
\text { Others }\end{array}$ & $.18^{*}$ & .03 & .02 & -.02 & $.14^{*}$ & $.12 *$ & $.17 *$ & $.07 *$ & $.16^{*}$ & $.30 *$ & $.38 *$ & $.29 *$ & $.23^{*}$ & 1 & $.68^{*}$ \\
\hline 15. & $\begin{array}{l}\text { Tries to } \\
\text { Understan } \\
\text { d Others }\end{array}$ & $.16^{*}$ & .01 & $.05^{*}$ & $-.02 *$ & $-13^{-}$ & $.11^{*}$ & $.20^{*}$ & $.05^{*}$ & $.15^{*}$ & $.26^{*}$ & $.37 *$ & $.29 *$ & $.24 *$ & $.68^{*}$ & 1 \\
\hline
\end{tabular}

a. Table 3 shows Bivariate Correlations between all Self-Regulation items used in the analysis. An (*) indicated a significant relationship. 
Table 4

Analysis of Covariance Attachment Classification and Emotional Regulation

\begin{tabular}{lccc}
\hline Source & $F$ & Sig & $\begin{array}{c}\text { Partial } \\
\text { Eta } \\
\text { Squared }\end{array}$ \\
\hline $\begin{array}{l}\text { Corrected } \\
\text { Model }\end{array}$ & 27.42. & .000 & .039 \\
Intercept & 4349.8 & .000 & .618
\end{tabular}


Table 5

Analysis of Covariance Attachment Classification and Cognitive Regulation

\begin{tabular}{lccc}
\hline Source & $F$ & Sig & $\begin{array}{c}\text { Partial } \\
\text { Eta } \\
\text { Squared }\end{array}$ \\
\hline $\begin{array}{l}\text { Corrected } \\
\text { Model }\end{array}$ & 44.836 & .000 & .063 \\
Intercept & 2518.764 & .000 & .484
\end{tabular}


Table 6

Analysis of Covariance Attachment Classification and Behavioral Regulation

\begin{tabular}{lccc}
\hline Source & $F$ & Sig & $\begin{array}{c}\text { Partial } \\
\text { Eta } \\
\text { Squared }\end{array}$ \\
\hline $\begin{array}{l}\text { Corrected } \\
\text { Model }\end{array}$ & 23.25 & .000 & .033 \\
Intercept & 3244.26 & .000 & .547
\end{tabular}


Table 7

Factor Analysis Table of Self-Regulation Items

\begin{tabular}{llll}
\hline & $\begin{array}{l}\text { Externalizing } \\
\text { Negativity }\end{array}$ & $\begin{array}{l}\text { Executive } \\
\text { Functioning }\end{array}$ & Social/Affective \\
Aggressive & .789 & & \\
Annoys Others & .782 & & \\
Temper Tantrums & .726 & & \\
Impulsivity & .656 & .71 & \\
Pays Attention & & .70 & .836 \\
Difficulty Concentrating & & .68 & .810 \\
Works Until Finished & & & .535 \\
Comforts Others & & & .433 \\
Tries to Understand Others & & & \\
Makes Friends Easily & & & \\
Accepted by Others & & & \\
\hline
\end{tabular}

From Dice, Shim, Hamilton-Jones, \& Hicks (manuscript in preparation) 


\begin{abstract}
APPENDICES
Resources Required

The Early Childhood Longitudinal Study-Birth Cohort dataset was needed for secondary analysis. . Although IRB approval was not needed for this design, I accesse the primary data through Jaime Dice. I used The Statistical Package for the Social Sciences (SPSS) to conduct the statistical analysis. This program is accessible through computers located on the University of Rhode Island Campus. The URI library database was also needed for access to scholarly journals that pertain to this research. Support and approval from Jaime Dice and my committee members was needed throughout the process of completing this thesis research project.
\end{abstract}




\section{BIBLIOGRAPHY}

Altamura, V. O. (2012). Influences of attachment, temperament, and emotional development on preschool children's behavior. Dissertation Abstracts International. 72(10) Retrieved from URI EBSCO host, 2012.

Andreassen, C., \& West, J. (2007). Measuring socioemotional functioning in a national birth cohort study. Infant Mental Health Journal, 28(6), 627-646.

Andreassen, C., Fletcher, P., Park, J. (2007). Early Childhood Longitudinal Study, Birth Cohort (ECLS-B). Psychometric Report for the 2-Year Data Collection (NCES 2007-084). Washington, DC: National Center for Health Statistics, Institute of Education Sciences, U.S. Department of Education.

Ashiabi, G. S. (2000). Promoting the emotional development of preschoolers. Early Childhood Education Journal, 28(2), 79-84. doi: 10.1023/A:1009543203089

Berger, A. (2011). Individual differences in self-regulation. In , Self-regulation: Brain, cognition, and development (pp. 61-90). Washington, DC US: American Psychological Association. doi:10.1037/12327-004

Berlin, L. J., \& Cassidy, J. (2003). Mothers' self-reported control of their preschool children's emotional expressiveness: A longitudinal study of associations with infant-mother attachment and children's emotion regulation. Social Development, 12(4), 477-495. doi: 10.1111/1467-9507.00244

Blair, C., \& Diamond, A. (2008). Biological processes in prevention and intervention: The promotion of self-regulation as a means of preventing school failure. Development and Psychopathology, 20(3), 899. 
Braungart, J. M., \& Stifter, C. A. (1991). Regulation of negative reactivity during the strange situation: Temperament and attachment in 12-month-old infants. Infant Behavior \& Development, 14(3), 349-364. doi: 10.1016/0163-6383(91)90027-P

Bretherton, I. (1992). The origins of attachment theory: John Bowlby and Mary Ainsworth. Developmental Psychology, 28(5), 759-775. doi: 10.1037/00121649.28.5.759

Campos, J. J., \& C. (1989). Emergent themes in the study of emotional development and emotion regulation. Developmental Psychology, 25, 394-402.

Carleton, J. A., \& Padolsky, I. (2012). Wilhelm reich's theoretical concept of motherinfant attachment as the origin of self-regulation: A neurophysiological perspective. Body, Movement and Dance in Psychotherapy, 7(2), 89-100. doi: $10.1080 / 17432979.2011 .592395$

Carter, A. S., Little, C., Briggs-Gowan, M., \& Kogan, N. (1999). The infant-toddler social and emotional assessment (ITSEA): Comparing parent ratings to laboratory observations of task mastery, emotion regulation, coping behaviors and attachment status. Infant Mental Health Journal, 20(4), 375-392. doi: 10.1002/(SICI)1097-0355(199924)20:4<375::AID-IMHJ2>3.0.CO;2-P

Carter, A. S., Little, C., Briggs-Gowan, M., \& Kogan, N. (1999). The infant-toddler social and emotional assessment (ITSEA): Comparing parent ratings to laboratory observations of task mastery, emotion regulation, coping behaviors and attachment status. Infant Mental Health Journal, 20(4), 375-392. doi: 10.1002/(SICI)1097-0355(199924)20:4<375::AID-IMHJ2>3.0.CO;2-P

Cassidy, J. (1994). Emotion regulation: Influences of attachment relationships. 
Monographs of the Society for Research in Child Development, 59(2-3), 228-283. doi: $10.2307 / 1166148$

Crugnola, C. R., Tambelli, R., Spinelli, M., Gazzotti, S., Caprin, C., \& Albizzati, A. (2011). Attachment patterns and emotion regulation strategies in the second year. Infant Behavior \& Development, 34(1), 136-151. doi:

10.1016/j.infbeh.2010.11.002

Denham, S., Bassett, H., Way, E., Mincic, M., Zinsser, K., \& Graling, K. (2012).

Preschoolers' emotion knowledge: Self-regulatory foundations, and predictions of early school success. Cognition and Emotion, 26(4), 667-679. doi:

$10.1080 / 02699931.2011 .602049$

Diamond, L. M., \& Fagundes, C. P. (2010). Psychobiological research on attachment. Journal of Social and Personal Relationships, 27(2), 218-225. doi: $10.1177 / 0265407509360906$

DiPerna, J. C., \& Volpe, R. J. (2005). Self-report on the social skills rating system: Analysis of reliability and validity for an elementary sample. Psychology in the Schools, 42(4), 345-354. doi: 10.1002/pits.20095

Drake, K., Belsky, J., \& Fearon, R. M. (2013). From Early Attachment to Engagement With Learning in School: The Role of Self-Regulation and Persistence.

Easterbrooks, M. A., \& Biringen, Z. (2000). Guest editors' introduction to the special issue: Mapping the terrain of emotional availability and attachment. Attachment \& Human Development, 2(2), 123-129. doi: 10.1080/14616730050085518

Edwards, M. C., Whiteside-Mansell, L., Connors, N. A., \& Deere, D. (2003). The unidimensionality and reliability of the preschool and kindergarten behavior 
scales. Journal of Psychoeducational Assessment, 21(1), 16-31. doi: $10.1177 / 073428290302100102$

Edwards, M. C., Whiteside-Mansell, L., Connors, N. A., \& Deere, D. (2003). The unidimensionality and reliability of the preschool and kindergarten behavior scales. Journal of Psychoeducational Assessment, 21(1), 16-31. doi:

$10.1177 / 073428290302100102$

Elliott, S. N., Gresham, F. M., Freeman, T., \& McCloskey, G. (1988). Teacher and observer ratings of children's social skills: Validation of the social skills rating scales. Journal of Psychoeducational Assessment, 6(2), 152-161. doi: $10.1177 / 073428298800600206$

Fantuzzo, J., Manz, P. H., \& McDermott, P. (1998). Preschool version of the social skills rating system: An empirical analysis of its use with low-income children. Journal of School Psychology, 36(2), 199-214. doi: 10.1016/S0022-4405(98)00005-3

Garner, P. W., \& Waajid, B. (2012). Emotion knowledge and self-regulation as predictors of preschoolers' cognitive ability, classroom behavior, and social competence. Journal of Psychoeducational Assessment, 30(4), 330-343. doi: $10.1177 / 0734282912449441$

Howse, R. B., Calkins, S. D., Anastopoulos, A. D., Keane, S. P., \& Shelton, T. L. (2003). Regulatory contributors to children's kindergarten achievement. Early Education and Development, 14(1), 101-120.

Kadzikowska-Wrzosek, R. (2012). Perceived stress, emotional ill-being and psychosomatic symptoms in high school students: the moderating effect of selfregulation competences. Archives of Psychiatry and Psychotherapy, 3, 25-33. 
Kidwell, S. L., Young, M. E., Hinkle, L. D., Ratliff, A. D., Marcum, M. E., \& Martin, C. N. (2010). Emotional competence and behavior problems: Differences across preschool assessment of attachment classifications. Clinical Child Psychology and Psychiatry, 15(3), 391-406. doi: 10.1177/1359104510367589

Kinniburgh, K. J., Blaustein, M., Spinazzola, J., \& van der Kolk, B. A. (2005). Attachment, Self-Regulation, and Competency. Psychiatric Annals. 35(5).

Kochanska, G., Philibert, R. A., \& Barry, R. A. (2009). Interplay of genes and early mother-child relationship in the development of self-regulation from toddler to preschool age. Journal of Child Psychology and Psychiatry, 50(11), 1331-1338. doi: 10.1111/j.1469-7610.2008.02050.x

Kohn, J. L., Rholes, W. S., \& Schmeichel, B. J. (2012). Self-regulatory depletion and attachment avoidance: Increasing the accessibility of negative attachment-related memories. Journal of Experimental Social Psychology, 48(1), 375-378. doi: 10.1016/j.jesp.2011.06.020

Kopp, C. B. (1982). Antecedents of self-regulation: A developmental perspective. Developmental Psychology, 18(2), 199-214. doi: 10.1037/0012-1649.18.2.199 Kotelchuck, M. (2009). Early childhood longitudinal study-birth cohort: A welcome addition to the maternal and child health field and its data bases. Maternal and Child Health Journal, 13(6), 715-719. doi: 10.1007/s10995-009-0517-7

Liew, J. (2012). Effortful control, executive functions, and education: Bringing selfregulatory and social-emotional competencies to the table. Child Development Perspectives, 6(2), 105-111. doi: 10.1111/j.1750-8606.2011.00196.x

Lisonbee, J. A., Pendry, P., Mize, J., \& Gwynn, E. P. (2010). Hypothalamic-pituitary- 
adrenal and sympathetic nervous system activity and children's behavioral regulation. Mind, Brain, and Education, 4(4), 171-181. doi: 10.1111/j.1751228X.2010.01096.x

McClelland, M. M., \& Tominey, S. L. (2011). Introduction to the special issue on selfregulation in early childhood. Early Education and Development, 22(3), 355-359. doi: $10.1080 / 10409289.2011 .574265$

McClelland, M. M., Ponitz, C. C., Messersmith, E. E., \& Tominey, S. (2010). Selfregulation: Integration of cognition and emotion. In W. F. Overton, \& R. M. Lerner (Eds.), The handbook of life-span development, vol 1: Cognition, biology, and methods. (pp. 509-553). Hoboken, NJ US: John Wiley \& Sons Inc. doi: 10.1002/9780470880166.hlsd001015

Merrell, K. W. (1995). An investigation of the relationship between social skills and internalizing problems in early childhood: Construct validity of the preschool and kindergarten behavior scales. Journal of Psychoeducational Assessment, 13(3), 230-240. doi: 10.1177/073428299501300302

Mikulincer, M. (1995). Attachment style and the mental representation of the self. Journal of Personality and Social Psychology, 69(6), 1203-1215. doi: $10.1037 / 0022-3514.69 .6 .1203$

Mikulincer, M., \& Shaver, P. R. (2005). Attachment security, compassion, and altruism. Current Directions in Psychological Science, 14(1), 34-38. doi: 10.1111/j.09637214.2005.00330.x

Mikulincer, M., Shaver, P. R., \& Pereg, D. (2003). Attachment theory and affect regulation: The dynamics, development, and cognitive consequences of 
attachment-related strategies. Motivation and Emotion, 27(2), 77-102.

Miljkovitch, R., Pierrehumbert, B., \& Halfon, O. (2007). Three-year-olds' attachment play narratives and their associations with internalizing problems. Clinical Psychology \& Psychotherapy, 14(4), 249-257. doi: 10.1002/cpp.535

Moss, E., Dubois-Comtois, K., Cyr, C., Tarabulsy, G. M., St-Laurent, D., \& Bernier, A. (2011). Efficacy of a home-visiting intervention aimed at improving maternal sensitivity, child attachment, and behavioral outcomes for maltreated children: A randomized control trial. Development and Psychopathology, 23(1), 195-210. doi: $10.1017 /$ S0954579410000738

Najarian, M., Snow, K., Lennon, J., \& Kinsey, S. (2010). Early Childhood Longitudinal Study, Birth Cohort (ECLS-B). Preschool-Kindergarten 2007 psychometric report (NCES 2010-009). Washington, DC: National Center for Health Statistics, Institute of Education Sciences, U.S. Department of Education.

National Center for Education Statistics. (2010). Preschool National Study: Early Care and Education Provider Interview. Early Child Longitudinal Program-ECLS. Retrieved February, 2013 from

$\underline{\text { http://nces.ed.gov/ecls/birthinstruments.asp }}$

Panfile, T. M., \& Laible, D. J. (2012). Attachment security and child's empathy: The mediating role of emotion regulation. Merrill-Palmer Quarterly, 58(1), 1-21. doi: 10.1353/mpq.2012.0003

Paulson, J. F., Keefe, H. A., \& Leiferman, J. A. (2009). Early parental depression and child language development. Journal of Child Psychology and Psychiatry, 50(3), 254-262. doi: 10.1111/j.1469-7610.2008.01973.x 
Ramani, G. B., Brownell, C. A., \& Campbell, S. B. (2010). Positive and negative peer interaction in 3-and 4-year-olds in relation to regulation and dysregulation. The Journal of Genetic Psychology, 171(3), 218-250.

Schultz, D., Izard, C. E., Ackerman, B. P., \& Youngstrom, E. A. (2001). Emotion knowledge in economically disadvantaged children: Self-regulatory antecedents and relations to social difficulties and withdrawal. Development and Psychopathology, 13(1), 53-67.

Smith, C. L., Calkins, S. D., \& Keane, S. P. (2006). The relation of maternal behavior and attachment security to toddlers' emotions and emotion regulation. Research in Human Development, 3(1), 21-31. doi: 10.1207/s15427617rhd0301_3

Sparks, P. J. (2009). One size does not fit all: An examination of low birthweight disparities among a diverse set of racial/ethnic groups. Maternal and Child Health Journal, 13(6), 769-779. doi: 10.1007/s10995-009-0476-z

Sparks, P. J. (2009). Do biological, sociodemographic, and behavioral characteristics explain racial/ethnic disparities in preterm births?. Social science \& medicine, 68(9), 1667-1675.

Tarullo, A. R., Obradovic, J., \& Gunnar, M. R. (2009). Self-control and the developing brain. Zero to Three, 29(3), 31.

Ursache, A., Blair, C., \& Raver, C. C. (2012). The promotion of self-regulation as a means of enhancing school readiness and early achievement in children at risk for school failure. Child Development Perspectives, 6(2), 122-128. doi: 10.1111/j.1750-8606.2011.00209.x

Van IJzendoorn, M. H., Vereijken, C. M., Bakermans-Kranenburg, M. J., \& Marianne 
Riksen-Walraven, J. (2004). Assessing attachment security with the attachment Q sort: Meta-analytic evidence for the validity of the observer AQS. Child development, $75(4), 1188-1213$

Vohs, K. D., \& Baumeister, R. F. (2011). Handbook of self-regulation: Research, theory, and applications (2nd ed.). New York, NY US: Guilford Press.

Volling, B. L., McElwain, N. L., Notaro, P. C., \& Herrera, C. (2002). Parents' emotional availability and infant emotional competence: Predictors of parent-infant attachment and emerging self-regulation. Journal of family psychology: JFP: journal of the Division of Family Psychology of the American Psychological Association (Division 43), 16(4), 447.

Waters, E., \& Deane, K. E. (1985). Defining and assessing individual differences in attachment relationships: Q-methodology and the organization of behavior in infancy and early childhood. Monographs of the Society for Research in Child Development, 50(1-2), 41-65. doi: 10.2307/3333826

Waters, S. F., Virmani, E. A., Thompson, R. A., Meyer, S., Raikes, H. A., \& Jochem, R. (2010). Emotion regulation and attachment: Unpacking two constructs and their association. Journal of Psychopathology and Behavioral Assessment, 32(1), 3747. doi: 10.1007/s10862-009-9163-z

Zimmermann, P., Mohr, C., \& Spangler, G. (2009). Genetic and attachment influences on adolescents' regulation of autonomy and aggressiveness. Journal of Child Psychology and Psychiatry, 50(11), 1339-1347. doi: 10.1111/j.14697610.2009.02158.x 